\title{
Tackling the silent epidemic of Type-I Diabetes Mellitus (Type-1 DM) through National Health Programmes- A narrative review of available evidence Om Prakash Bera, Vandana Shah, Sudip Bhattacharya, Sheikh Mohd Saleem
}

${ }^{1}$ Principal Consultant (Implementation), Global Health Advocacy Incubator, India; ${ }^{2}$ Regional Director (Southeast Asia), Global Health Advocacy Incubator, ${ }^{3}$ Independent Global Public Health Researcher, Dehradun, India; ${ }^{4}$ Independent Global Public Health Researcher, Srinagar, Jammu \& Kashmir, India.

\begin{tabular}{|c|c|c|c|c|c|c|c|c|}
\hline Abstract & Introduction & Methodology & Results & Conclusion & References & Citation & \multicolumn{2}{|c|}{ Tables / Figures } \\
\hline \multicolumn{9}{|c|}{ Corresponding Author } \\
\hline \multicolumn{8}{|c|}{$\begin{array}{l}\text { Dr Sudip Bhattacharya, C5/12, HIHT Campus, Jolly Grant, Swami Rama Himalayan University, Dehradun, Pin- } \\
\text { 248140, India } \\
\text { E Mail ID: } \underline{\text { drsudip84@gmail.com }}\end{array}$} & 口ifing \\
\hline
\end{tabular}

\section{Citation}

Bera OP, Shah V, Bhattacharya S, Saleem S. Tackling the silent epidemic of Type-I Diabetes Mellitus (Type-1 DM) through National Health Programmes- A narrative review of available evidence. Indian J Comm Health. 2021;33(2):245-249. https://doi.org/10.47203/IJCH.2021.v33i02.004

Source of Funding: Nil Conflict of Interest: None declared

\section{Article Cycle}

Received: 09/04/2021; Revision: 25/05/2021; Accepted: 13/06/2021; Published: 30/06/2021

This work is licensed under a Creative Commons Attribution 4.0 International License.

\section{Abstract}

Type 1 diabetes mellitus (T1DM) is an autoimmune $\beta$-cell destruction, usually leading to absolute insulin deficiency, insulin resistance, or by a combination of both. Both the incidence and prevalence of diabetes T1DM is suspected to be high in India, but in the absence of nation-wide registry, the possibility of exact numbers is unsure. Till date, studies done among the population have seen prevalence more than the incidence of the disease, which has led to late screening and diagnosis of the disease within the community settings. India is already suffering from the burden of type $2 \mathrm{DM}$, in the process of screening those, patients with T1DM are somewhat getting ignored. Furthermore, cost associated with the treatment expenditure and social status of the people suffering from the disease too have a role to consider which has been totally side-lined in national programmes like National Program for Control of Diabetes, Cardiovascular disease, and Stroke (NPCDCS). There is also scarcity of data on the incidence of T1DM which could aid in formulating better policy avenues for the patients suffering from the disease. Reports on trends in T1DM are more commonly available from countries with better established public health surveillance systems and diabetes research infrastructure. From India, due to scarcity of data on T1DM, we had to rely on published literature of some major centers across the country. Results from the Indian Council of Medical Research (ICMR) first phase, till July 2011 which included 5546 patients found T1DM among 63.9\% cases and predominately among children; at registration $11.1 \%$ had already developed chronic complication of T1DM. As India is already suffering from the burden of type $2 \mathrm{DM}$, during current management and treatment, the problem lies at various levels which needs to be addressed. We propose a setting based, life course approach for T1DM where every age group will have access to the health care system either directly or indirectly from intra-natal life till elderly age group through health approach based on scientific methods delivered through health system. In this regard a central registry having enumeration and provisioning of mandatory Insulin to all through a national policy being implemented by NPCDCS is what policy makers must take up at urgent bases if we want to bend the curve of rising T1DM and prevalence of overall diabetes in India.

\section{Keywords}

Diabetes Mellitus, Type 1; Incidence; Prevalence; Insulin Resistance; Public Health Surveillance; India; Publications; Government Programs; Preservation, Biological; Biomedical Research; Diabetes Mellitus, Type 2; Delivery of; Health Care

\section{Introduction}

The American Diabetes Association (ADA) defines "type 1 diabetes mellitus (T1DM) as autoimmune $\beta$-cell destruction, usually leading to absolute insulin deficiency insulin resistance, or by a combination of both" (1). This form of diabetes accounts for only $5-10 \%$ of the cases with diabetes worldwide. Damage or loss to the functional capacity of the $\beta$-cell mass has been found to be the key mechanism leading to $\mathrm{DM}$, and if $\beta$-cells are able to 
compensate for insulin resistance, normoglycemia is preserved within the body (2).

Previously, known to us by many other names like insulindependent diabetes mellitus, juvenile-onset diabetes, this form of diabetes results from a cell-mediated immune response that causes auto-destruction of the pancreatic $\beta$-cells (3). Although numerous studies have been performed to identify the main causative factors involved in the disease causation, the complete picture is yet to be determined. Based on these studies, type 1 DM was considered an autoimmune disease related to genetics and involving immunological and environmental factors (4-5).

The outline of various modern treatment options available for type 1 DM are illustrated in [Table 1].

Both the incidence and prevalence of diabetes type 1 and 2 is suspected to be high in India, but in the absence of nation-wide registry, the possibility of exact numbers is unsure. Till date studies done among the population have seen prevalence more than the incidence of the disease, which has led to late screening and diagnosis of the disease within the community settings. India is already suffering from the burden of type $2 \mathrm{DM}$, in the process of screening those, patients with type 1 diabetes are somewhat getting ignored. Furthermore, cost associated with the treatment expenditure and social status of the people suffering from the disease too have a role to consider which has been totally side-lined in national programmes like NPCDCS. There is also scarcity of data on the incidence of type 1 diabetes mellitus which could aid in formulating better policy avenues for the patients suffering from diabetes type-1.

\section{Aim \& Objective}

To analyze the ongoing health programmes/policies for type 1 diabetes in India and we will discuss what are the window of opportunities we must address the issue of diabetes mellitus type-1 in India.

\section{Material \& Methods}

We searched the MEDLINE, PsycINFO, Scopus, Web of Science, and Google scholar databases using the following keywords: ("diabetes") and (diabetes mellitus), (type 1 diabetes), (nutritional programmes in India), (Health policies in India), (juvenile diabetes in India). We used these key words in combination with each other and in truncated form. All the relevant articles and policy documents (MOHFW, INDIA) available in the public domain from 2005 were included to support the argument for this narrative review. The researchers extracted relevant data, including, study purpose, design, sample, methods, and findings reported by study authors and summarized as below.

\section{Results \& Discussion}

Reports on trends in Type 1 DM are more commonly available from countries with better established public health surveillance systems and diabetes research infrastructure. Here we report on the global burden of type 1 DM (incidence and prevalence), finding taken from the systemic review by Mobasseri $M$ et al. (6) The incidence was found to be 15 per 100000 population $[\mathrm{Cl}=0.010$ to 0.021$]$ and the prevalence was 6.9 per 10000 population $[\mathrm{Cl}=0.020$ to 0.214$]$. Both incidence and prevalence were found to be statistically significant at $95 \% \mathrm{Cl}(6)$.

In African continent, the incidence was found to be almost half than the Asian continent i.e., 8 per 100000 population $[\mathrm{Cl}=0.003$ to 0.021$]$ while prevalence was 3.5 per 10000 population [0.022 to 0.055]. Although incidence was found to be statistically significant while incidence rates were not (6). Like Asian continent, European continent has incidence of type $1 \mathrm{DM}$ like 15 per 100000 population $[\mathrm{Cl}=0.013$ to 0.018$]$, while with the higher prevalence rates than the Asian continent with 12.2 per 10000 population $[\mathrm{Cl}=0.085$ to 0.171$]$ suffering from type $1 \mathrm{DM}$. Both the incidence and prevalence were found to be statistically significant (6). Among all the continents, the incidence of type $1 \mathrm{DM}$ was found to be higher in American continent with 20 per 100000 population $[\mathrm{Cl}=0.010$ to 0.021$]$, and the prevalence of type 1 diabetes was 12.2 per 10000 population $[\mathrm{Cl}=0.063$ to 0.137$]$. Both the incidence and prevalence were found to be statistically significant (6). The incidence of type 1 diabetes in world was 15 per 100000 population, which was statistically significant $[\mathrm{Cl}=0.013$ to 0.017$]$, and the prevalence of type 1 diabetes was 9.5 per 10000 population, which was statistically significant $[\mathrm{Cl}=0.070$ to 0.128] (6). An initial attempt to determine the prevalence of type $1 \mathrm{DM}$ among children was carried out in northern part of Madras (now called Chennai), in one of the southern states of India, Tamil Nadu. The data was collected based on the individual cases identified from hospitals, private clinics etc. Only 30 cases were identified, giving a prevalence of just 0.261 (7). Later, a diabetes registry was established in the same city and incidence of type 1 DM found to be 12.6 and 9.6 per 100000 boys and girls per year, over a 4-year period [1991-94] (8). On a similar analogy, the neighboring state Karnataka also started a diabetic register and started collected data on type $1 \mathrm{DM}$ for 13 long years but reported incidence of mere 3.7 and 4.0 per 100000 boys and girls respectively. However, the low incidence of type 1 DM may have been due to incomplete reporting or under reporting from many parts of the larger state (9). In the state of Haryana, a single endocrine site hospital-based study was conducted which reported prevalence of type 1 DM among the entire population. The study reported overall prevalence of 10.2 per 100000 population with wider male: female and rural: urban descendants. In the Karnal city alone, the prevalence was found to be 31.9 per 100 000; In urban areas it was 26.6 per 100000 while in rural areas it was 4.27 per 100000 population (10). Similar 
gradients were seen among different genders where males reported prevalence of 11.56 per 100000 population while females reported prevalence of 8.6 per 10000 population (10). The prevalence in 5-14 age group was found to be much higher, 24.22 per 100000 population, while it was only 3.83 per 100000 in 0-6-year age group. The total prevalence among the cohort of 0-14 age group was 18.27 per 100000 (10). The astonishing results from the state of Haryana suggested lack of medical facilities in the rural areas for children with type 1 DM which could have aided in early diagnosis and appropriate medical treatment at the right time. Moreover, the male female discrepancy in the prevalence reflected the underlying female gender discrimination.

Due to scarcity of data on type 1 diabetes, we had to rely of published literature on some major centers across the country. In 2004, Bhatia et al. (11) reported a prevalence of $81 \%$ type 1 diabetes among 160 diabetics aged less than 18 years. With an aim to set up a nationwide registry for people with young onset diabetes, Indian council of medical research (ICMR) funded a project in 2006 and enrolled all young cases residing within the geographical areas of eight collaborating sites across the country. The registry collects data on age of onset of diabetes, presentation of the disease, treatment pattern, prescribed insulin regimens, associated complications, infections, and modes of mortality among the patients (12). Results from the ICMR first phase, till July 2011 which included 5546 patients, were as follows: type 1 diabetes was found among $63.9 \%$ cases and predominately among children; at registration $11.1 \%$ had already developed chronic complication of type 1 diabetes and $11 \%$ patients had suffered attacks of hypoglycemia (12).

As most of the studies done so far have seen prevalence rather than incidence of type 1 diabetes, this has led to late diagnosis of the disease, putting strain on the health care system. As India is already suffering from the burden of type 2 DM (13), in the process of screening those, patients with type 1 diabetes are somewhat getting ignored. Rather, even after establishing the nationwide registry for those suffering from type 1 diabetes, the advantage of the ascertainment could only be localized to tertiary care institutions where the handful of population is able to take advantage of the facility. The move to expand the services of the registry in still under consideration throughout the country. The problem and difference lie in the screening and diagnosis between the type 1 and type 2 diabetes where the latter is easily screened and diagnosed by a primary health care worker at a remote subcenter while the former requires an endocrinologist and a special facility infrastructure to screen and diagnose the disease.

Another aspect lies at the cost expenditure by the patients on diabetes treatment. A systemic review by Oberoi $S$ et al. (14) reports on a total of thirty-two studies. From the north zone of India, the median direct cost of diabetes was estimated to be ₹18,890/- p.a., ₹10,585/- p.a. for the south zone, ₹45,792/- p.a. for the north-east zone and ₹8822/- p.a. for the west zone. Similarly, the median indirect cost of diabetes was ₹18,146/- p.a. for the north zone, ₹1198/- p.a. for the south zone, ₹18,707/- p.a. for the north-east and ₹3949/- p.a. for the west zone respectively (14). It is quite evident that such a huge cost expenditure on diabetes treatment diabetes poses a high economic burden on individuals/households. In India, $12.4 \%$ of people are extremely poor as they earn a total of rupees 150 or less per head per day only (15). They are living under "Below Poverty Line" which is a benchmark used by the government of India to indicate economic disadvantage and to identify individuals and households in need of government assistance and aid. It is determined using various parameters which vary from state to state and within states. So, it is difficult for them to manage the treatment cost of the type- 1 diabetes and it requires lifelong treatment (in the form of insulin which is not freely given from the hospitals) so the BPL patients pushed further below the BPL due to the catastrophic expenditure (15). During current management and treatment, the problem lies at provider and recipient levels: A well know program against non-communicable diseases, National Programme for prevention \& Control of Cancer, Diabetes, Cardiovascular Diseases \& stroke (NPCDCS) has been running successfully since 2010 but there is no mention of type 1 diabetes even after such a huge burden of case within the country. The scope of genetic counselling among those parents suffering from type 1 diabetes is only restricted to metropolitan cities, government affiliated premier institutes or private hospitals. No such provision has been made to include type 1 diabetes in the national programme, no such training to the health workers has been provided to deal with the cases or no such funding has been reserved to such a cause. At the recipient level, parents suffering from type 1 diabetes are usually unaware about the future course of the disease, marriage counselling methods, family planning methods, baby counselling, genetic counselling, and regular follow up except in some metropolitan cities, government affiliated premier institutes and private hospitals where they can avail these kinds of facilities.

\section{Recommendations}

[Table 2] While we propose solutions to the everneglected area of non-communicable diseases i.e., type 1 diabetes, we must bear in mind a famous proverb, "a stich in time can save nine". The already overburdened health infrastructure of our country cannot be overstretched to bear the responsibility alone, a multisectoral approach is needed which is outlines in table 2 . We propose a setting based, life course approach where every age group will have access to the health care system for type - 1 diabetes, either directly or indirectly. Right from the intra-natal period, mother can have access to genetic counselling at 
hospitals through genetic counselors if the same is introduced in the national programme NPCDCS. In a similar way, babies born to diabetic mother can have genotyping done in hospital settings recommended through pediatricians under RBSK programme, identifications of early signs of diabetes like polyuria, polydipsia, polyphagia etc. and lifestyle behavioral modifications can be encouraged among children under 6 years of age through anganwadi workers under ICDS. Health subcenters and health and wellness centers can be a source of data generation and surveillance through ASHAs and ANMs where they can easily screen children and adolescents for early signs of diabetes under NPCDCS and RKSK programmes. Health and wellness ambassadors in schools and educational institutions are the best nominated individuals who can identify high risk children and adolescent prone to suffer from diabetes in future. Under NPCDCS, community screening is done using CBAC form for the population greater than 30 years of age, the same can be done for all age groups within each household to include type $1 \mathrm{DM}$ screening under the same banner of NPCDCS. The co-ordination between the NPCDCS, RBSK, National Tuberculosis Elimination program (NTEP) and National AIDS Control program (NACP) needs to be strengthened, data sharing and treatment outcome needs to be streamlined. Nevertheless, data collection on juvenile diabetes needs to be included in nationwide periodic surveys like national family health survey (NFHS) and district level health surveys (DLHS) which will not only strengthen our data system but also help us to identify the trend and other variable affecting the disease progression over the time. Moreover, there is one important fact to acknowledge that every research institute or hospital is maintaining its own diabetic registry for surveillance or data record keeping. A uniform registry based on common motive and goal should be maintained across the country with periodic monitoring and evaluation. Last but not the least, ensuring regular insulin supply, free of cost, from government hospital is urgently required. In this regard a central registry having enumeration and provisioning of mandatory free supply of Insulin to all through a national policy being implemented by NPCDCS is what policy makers must take up at urgent basis if we want to bend the curve of rising type-1 diabetes and prevalence of overall diabetes in India.

\section{Limitation of the study}

It is a narrative review; it will be better if we could perform a systemic review and metanalysis on this topic.

\section{Relevance of the study}

Our study highlights the window of opportunity to address the issue of type-1 diabetes in India through existing health programmes and policies.

\section{Authors Contribution}

Concept and design-SB, OPB and VS. First draft-SMS and SB. Editing-SB, SMS, VS and OPB.

\section{Acknowledgement}

The authors would like to thank all the authors of those books, articles, and journals that were referred in preparing this manuscript.

\section{References}

1. Classification and diagnosis of diabetes: standards of medical care in diabetes - 2019. Diabetes Care 42 (Suppl. 1), 13-28 (2019)

2. Cnop, M. et al. Mechanisms of pancreatic $\beta$-cell death in type 1 and type 2 diabetes: many differences, few similarities. Diabetes 54 (Suppl. 2), 97-107 (2005). 2. American Diabetes Association.

3. American Diabetes Association. Diagnosis and classification of diabetes mellitus [published correction appears in Diabetes Care. 2010 Apr;33(4):e57]. Diabetes Care. 2010;33 Suppl 1(Suppl 1):S62S69. doi:10.2337/dc10-S062

4. Al-Mutairi HF, Mohsen AM, Al-Mazidi ZM. Genetics of type I diabetes. Kuwait Med J 2007;39:107e15.

5. Pociot F, McDermott MF. Genetics of type 1 diabetes mellitus. Genes Immun 2002;3:235e49

6. Mobasseri M, Shirmohammadi M, Amiri T, Vahed N, Hosseini Fard $\mathrm{H}$, Ghojazadeh M. Prevalence and incidence of type 1 diabetes in the world: a systematic review and meta-analysis. Health Promot Perspect. 2020 Mar 30;10(2):98-115. doi: 10.34172/hpp.2020.18. PMID: 32296622; PMCID: PMC7146037.

7. Ramachandran A, Snehalatha C, Abdul Khader OM, Joseph TA, Viswanathan M. Prevalence of childhood diabetes in an urban population in south India. Diabetes Res Clin Pract. 1992;17:227-31.

8. Ramachandran A, Snehalatha C, Krishnaswamy CV. Incidence of IDDM in children in urban population in southern India. Madras IDDM Registry Group Madras, South India. Diabetes Res Clin Pract. 1996;34:79-82.

9. Kumar P, Krishna P, Reddy SC, Gurappa M, Aravind SR, Munichoodappa C. Incidence of type 1 diabetes mellitus and associated complications among children and young adults: results from Karnataka Diabetes Registry 1995-2008. J Indian Med Assoc. 2008;106:708-11.

10. Kalra S, Kalra B, Sharma A. Prevalence of type 1 diabetes mellitus in Karnal district, Haryana state, India. Diabetol Metab Syndr. 2010;2:14.

11. Bhatia V, Arya V, Dabadghao P, Balasubramanian K, Sharma K, Verghese $\mathrm{N}$, et al. Etiology and outcome of childhood and adolescent diabetes mellitus in North India. J Pediatr Endocrinol Metab. 2004;17:993-9.

12. The Indian Council of Medical Research (ICMR), India. Executive Summary: The Indian Council of Medical Research Registry of People with Diabetes with Young Age at Onset (ICMR-YDR), Phase 1 (2006-2011) Report. Available from: http://www.icmr.nic.in/sites/default/files/reports/Executive\%20s ummary. Accessed June 14, 2021.

13. Vijayakumar, G., Manghat, S., Vijayakumar, R. et al. Incidence of type 2 diabetes mellitus and prediabetes in Kerala, India: results from a 10-year prospective cohort. BMC Public Health 19, 140 (2019). https://doi.org/10.1186/s12889-019-6445-6

14. Oberoi S, Kansra P. Economic menace of diabetes in India: a systematic review. Int J Diabetes Dev Ctries. 2020 Jun 17:1-12. doi: 10.1007/s13410-020-00838-z. Epub ahead of print. PMID: 32837090; PMCID: PMC7299136.

15. Poverty and Equity - India The World Bank (2012) 
Tables

\section{TABLE 1 TREATMENT MODALITIES AVAILABLE FOR TYPE 1 DIABETES MELLITUS}

\begin{tabular}{|c|c|}
\hline \multirow[t]{3}{*}{ A } & Therapeutic Approaches \\
\hline & Gene therapy \\
\hline & $\begin{array}{l}\text { Diabetic therapy targeting } \beta \text {-cells \& } \beta \text {-cells regeneration } \\
\text { - Trans differentiation } \\
\text { - } \\
\text { - } \\
\text { - }\end{array}$ \\
\hline B & Non-pharmacological approach \\
\hline $\mathbf{C}$ & $\begin{array}{l}\text { Pharmacological approach } \\
\text { - Insulin } \\
\text { - } \text { Biguanides } \\
\text { - Sulfonylureas } \\
\text { - Thiazolidinediones } \\
\text { - Dipeptidylpeptidase-4 inhibitors } \\
\text { - Glucagon like peptide } 1 \text { (GLP-1) analogues } \\
\text { - Sodium-glucose co-transporter-2 (SGLT2) inhibitors } \\
\text { - Combination Therapy }\end{array}$ \\
\hline
\end{tabular}

TABLE 2 PROPOSED SOLUTION FOR TACKLING TYPE-1 DIABETES MELLITUS THROUGH SETTING BASED APPROACH (LIFE-CYCLE APPROACH)

\begin{tabular}{|c|c|c|c|c|}
\hline Setting & Approach & To whom & Through & Programme \\
\hline Hospital & Genetic counselling & Diabetic Mother & $\begin{array}{l}\text { Genetic } \\
\text { counselors }\end{array}$ & (NPCDCS) \\
\hline Hospital & Genotyping of Infant & Diabetic Mother & Pediatricians & $\begin{array}{l}\text { Rashtriya Bal Swasthya } \\
\text { Karyakram (RBSK) }\end{array}$ \\
\hline Anganwadi center & $\begin{array}{l}\text { Identification of early } \\
\text { signs of diabetes, } \\
\text { Encourage life style } \\
\text { behavioral changes and } \\
\text { management }\end{array}$ & $\begin{array}{l}\text { Children up to age } 6 \\
\text { years }\end{array}$ & $\begin{array}{l}\text { Anganwadi } \\
\text { Workers }\end{array}$ & $\begin{array}{l}\text { Integrated Child } \\
\text { Development Services } \\
\text { (ICDS) }\end{array}$ \\
\hline $\begin{array}{l}\text { Health sub-center } \\
\text { or health and } \\
\text { wellness center }\end{array}$ & $\begin{array}{l}\text { Spot Test method, Strip } \\
\text { method, Glucometer } \\
\text { test method }\end{array}$ & $\begin{array}{l}\text { Children and } \\
\text { Adolescents }\end{array}$ & ASHAs and ANMs & $\begin{array}{l}\text { NPCDCS, Rashtriya Kishor } \\
\text { Swasthya Karyakram (RKSK) }\end{array}$ \\
\hline $\begin{array}{l}\text { Schools \& } \\
\text { Educational } \\
\text { Institutions }\end{array}$ & $\begin{array}{l}\text { Identify early symptoms, } \\
\text { screening of blood sugar } \\
\text { among high risk }\end{array}$ & High risk children & $\begin{array}{l}\text { Health and } \\
\text { Wellness } \\
\text { ambassadors }\end{array}$ & School Health Programmes \\
\hline $\begin{array}{l}\text { Community and } \\
\text { National level }\end{array}$ & $\begin{array}{l}\text { Community based } \\
\text { assessment checklist } \\
\text { (CBAC) form }\end{array}$ & $\begin{array}{l}<30 \text { years old who } \\
\text { are at high risk, } \\
\text { having history of } \\
\text { diabetes in family }\end{array}$ & $\begin{array}{l}\text { ASHAs, ANMs, } \\
\text { Medical Officers }\end{array}$ & NPCDCS \\
\hline
\end{tabular}

